National Marine

Fisheries Service

Fishery Bulletin

Spencer F. Baird

NOAA

as established in 1881 ๙

\begin{abstract}
Determining movement, behavior, and activity patterns is of central importance to conservation efforts for threatened and endangered species because this knowledge is crucial for prioritizing management actions. In this study, we used acceleration data loggers (ADLs) concurrently with passive acoustic monitoring to examine behavior, activity patterns, and habitat use of juvenile smalltooth sawfish (Pristis pectinata) in a Florida nursery. Data from the ADLs indicate that smalltooth sawfish were more active and that more burst events indicative of foraging occurred during the evening and night than during the day. Smalltooth sawfish were also most active at depths $<1 \mathrm{~m}$ and during low tides. The locations of individuals derived from acoustic monitoring techniques indicate that they were less active while in mangrove creek habitats and were more active and more likely to engage in burst activity in habitats within the main stem of the Peace River. This study is the first one to deploy ADLs on smalltooth sawfish, and results describe their fine-scale activity and behavior, clarifying patterns of habitat use by this endangered species in one of their few remaining nurseries.
\end{abstract}

Manuscript submitted 19 March 2019. Manuscript accepted 7 November 2019. Fish. Bull. 117:348-359 (2019).

Online publication date: 17 December 2019. doi: 10.7755/FB.117.4.7

The views and opinions expressed or implied in this article are those of the author (or authors) and do not necessarily reflect the position of the National Marine Fisheries Service, NOAA.

\section{Fine-scale behavior and habitat use of the endangered smalltooth sawfish (Pristis pectinata): insights from accelerometry}

\author{
Karissa O. Lear (contact author) ${ }^{1,2}$ \\ Gregg R. Poulakis ${ }^{3}$ \\ Rachel M. Scharer ${ }^{3}$ \\ Adrian C. Gleiss ${ }^{2}$ \\ Nicholas M. Whitney ${ }^{1,4}$ \\ Email address for contact author: k.lear@murdoch.edu.au \\ ${ }^{1}$ Behavioral Ecology and Physiology Program \\ ${ }^{3}$ Charlotte Harbor Field Laboratory \\ Mote Marine Laboratory \\ 1600 Ken Thompson Parkway \\ Sarasota, Florida 34236 \\ ${ }^{2}$ Centre for Sustainable Aquatic Ecosystems \\ Harry Butler Institute \\ Murdoch University \\ 90 South Street \\ Murdoch, Western Australia 6150, Australia
}

Sawfish species compose what is considered one of the most threatened groups of chondrichthyans worldwide, with all 5 species listed as endangered or critically endangered by the International Union for the Conservation of Nature (IUCN) (Dulvy et al., 2014, 2016). The smalltooth sawfish (Pristis pectinata) is a coastal elasmobranch that inhabits estuaries and nearshore environments in the western Atlantic Ocean and Gulf of Mexico. Once common in the United States from Texas to North Carolina (Bigelow and Schroeder, 1953), this species is now restricted to less than $20 \%$ of its former range (Dulvy et al., 2016). Like that of other sawfish species, the decline in this population can largely be attributed to mortality from bycatch because their rostrum is easily entangled in fishing gear. Declines in populations of sawfish species have also been partially attributed to habitat destruction (Dulvy et al., 2016). In 2003, the smalltooth sawfish was federally protected and listed as endangered under the U.S. Endangered Species Act (Federal Register, 2003), and this species is listed as critically endangered on the IUCN Red List of Threatened Species (Carlson et al., 2013).

Although there is widespread concern regarding the protection and rebuilding of populations of smalltooth sawfish, little is known about their behavior and activity patterns. Previous studies have determined that smalltooth sawfish use the lower reaches of rivers, estuaries, and coastal bays as nurseries for about the first 3 years of life (Scharer et al., 2012). This species is particularly vulnerable to anthropogenic factors during this part of the juvenile stage, given that most of their known nurseries are surrounded by developed areas or subject to multiple fisheries (Norton et al., 2012). As a result, interactions with humans or recreational fishing gear are common (Seitz and Poulakis, 2006), and habitat destruction, pollution, and coastal 
developments are likely to have substantial, cumulative negative effects. Additionally, the high site fidelity of juveniles (Poulakis et al., 2016; Huston et al., 2017) means that these fish must cope with a wide range of environmental conditions (Poulakis et al., 2011, 2013), including extreme weather events (Scharer et al., 2017; Poulakis and Grubbs, 2019).

Acoustic tracking and monitoring of smalltooth sawfish in nursery habitats has provided valuable information regarding the long-term horizontal movement patterns of these animals (e.g., Simpfendorfer et al., 2011; Poulakis et al., 2013; Scharer et al., 2017); for example, this technique has been used to identify hotspots that represent the most productive habitats within nurseries (Poulakis et al., 2011, 2013; Huston et al., 2017). However, acoustic monitoring provides information only about the use of horizontal space by individuals, and as a result, little is known about the behavior of smalltooth sawfish or why they use specific microhabitats within their nurseries. One method of determining such fine-scale behavioral patterns is to use acceleration data-loggers (ADLs), which in recent years have been proven to be effective in linking behavior and physiology of species similar to the smalltooth sawfish (Gleiss et al., 2017; Whitney et al., 2018). This technology can be used to produce information about behavior and activity patterns without the need to continuously track or observe individuals.

In this study, to determine fine-scale habitat use and behavioral patterns, we deployed triaxial ADLs and acoustic transmitters concurrently on juvenile smalltooth sawfish in the Peace River, Florida, one of the known nurseries for this species. Behavioral and activity patterns measured by the ADLs were examined in combination with horizontal movement patterns measured by the acoustic transmitters, and the results of this analysis provide information on how smalltooth sawfish used specific habitats and depth ranges within this nursery.

\section{Materials and methods}

Between May 2014 and November 2015, 10 smalltooth sawfish were caught in gill nets with 152-mm stretch meshes in the Peace River (Fig. 1). Nets were set for $1 \mathrm{~h}$ and constantly monitored. As soon as a sawfish was caught, it was carefully removed from the net, measured for stretch total length (STL) in millimeters, and tagged. All individuals were tagged with $1 \mathrm{ADL}$ and at least 1

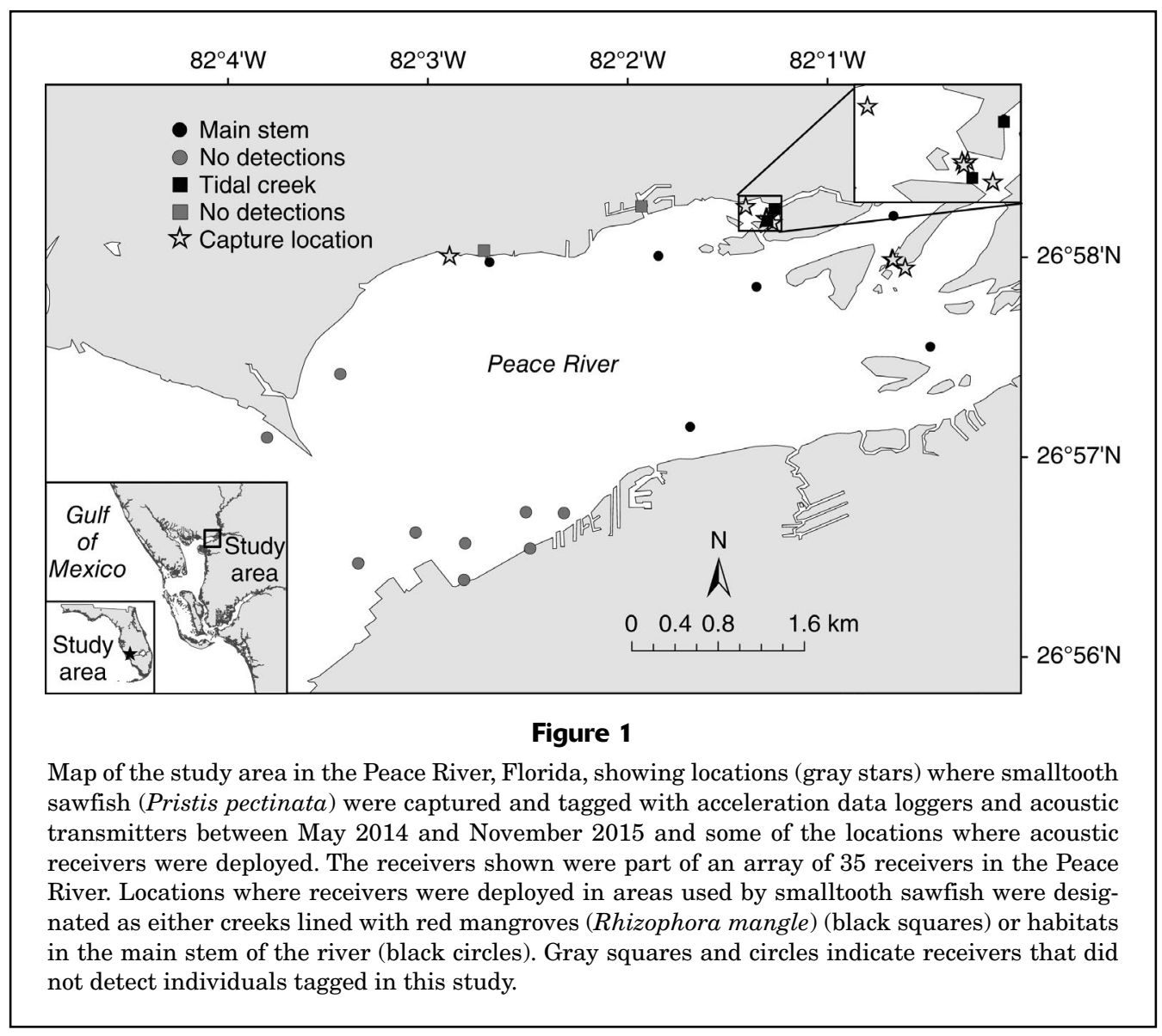


acoustic transmitter. The ADLs (G6a+ ${ }^{1}$, Cefas Technology Ltd., Lowestoft, UK) were programmed to record triaxial acceleration at $25 \mathrm{~Hz}$, depth at $1 \mathrm{~Hz}$, and temperature at $0.033 \mathrm{~Hz}$. If possible, ADLs were paired with externally attached continuous acoustic transmitters (V9, Vemco, Bedford, Canada) with 5-s delays, to facilitate recovery of the ADLs through recapture after 5-7 d. Most of these tags were attached to the first dorsal fin directly by using monofilament (Fig. 2A). Alternatively, 2 ADLs were indirectly attached to the dorsal fin of individuals by tethering them to custom float packages (Fig. 2B). Float packages incorporated both a very high frequency (VHF) transmitter (MM110, Advanced Telemetry Systems Inc., Isanti, $\mathrm{MN}$ ) and a galvanic timed release (GTR; International Fishing Devices Inc., Jupiter, FL). The GTRs were set to corrode after approximately $7 \mathrm{~d}$, allowing the float package to detach and rise to the surface, where the VHF transmitter facilitated recovery following the technique of Lear and Whitney (2016), and eliminating the need for recapture.

All animals were tagged with a coded $69-\mathrm{kHz}$ acoustic transmitter (V9), which was epoxied to a rototag and externally attached to the second dorsal fin following the methods of Poulakis et al. (2013). These transmitters emitted unique acoustic signals on a random delay between 80 and $160 \mathrm{~s}$ to minimize interference of signals from multiple tags and to maximize battery life. These transmitters communicated to an array of 35 omnidirectional VR2W acoustic receivers (Vemco) placed throughout the Peace River estuary (Fig. 1). They were also used to facilitate recovery of the ADLs through recapture if necessary. After tagging, smalltooth sawfish were released at their site of capture.

Work with animals was conducted under endangered species permit no. 15802, issued by the National Marine Fisheries Service.

\section{Data processing and analyses: data loggers}

Once ADLs were recovered, raw data were downloaded from them and prepared for analysis by using Igor Pro (vers. 6.22; WaveMetrics Inc., Portland, OR) and the application Ethographer (Sakamoto et al., 2009). Data from the first $12 \mathrm{~h}$ of ADL deployments were excluded to eliminate any behavioral effects of capture stress following tagging and release (Whitney et al., 2012). Static and dynamic acceleration were separated by using a 3-s box smoother, which was sufficient to remove the tailbeat signal from the static acceleration traces (Shepard et al., 2008), and both components were used to analyze body movement and position throughout the monitoring periods. $K$-means clustering analyses were run on the sway (tailbeat) acceleration axis to separate resting and active periods (Sakamoto et al., 2009; Whitney et al., 2010). Overall dynamic body acceleration (ODBA) (Wilson et al., 2006; Gleiss et al., 2011) was calculated as the sum of the absolute value of

\footnotetext{
${ }^{1}$ Mention of trade names or commercial companies is for identification purposes only and does not imply endorsement by the National Marine Fisheries Service, NOAA.
}

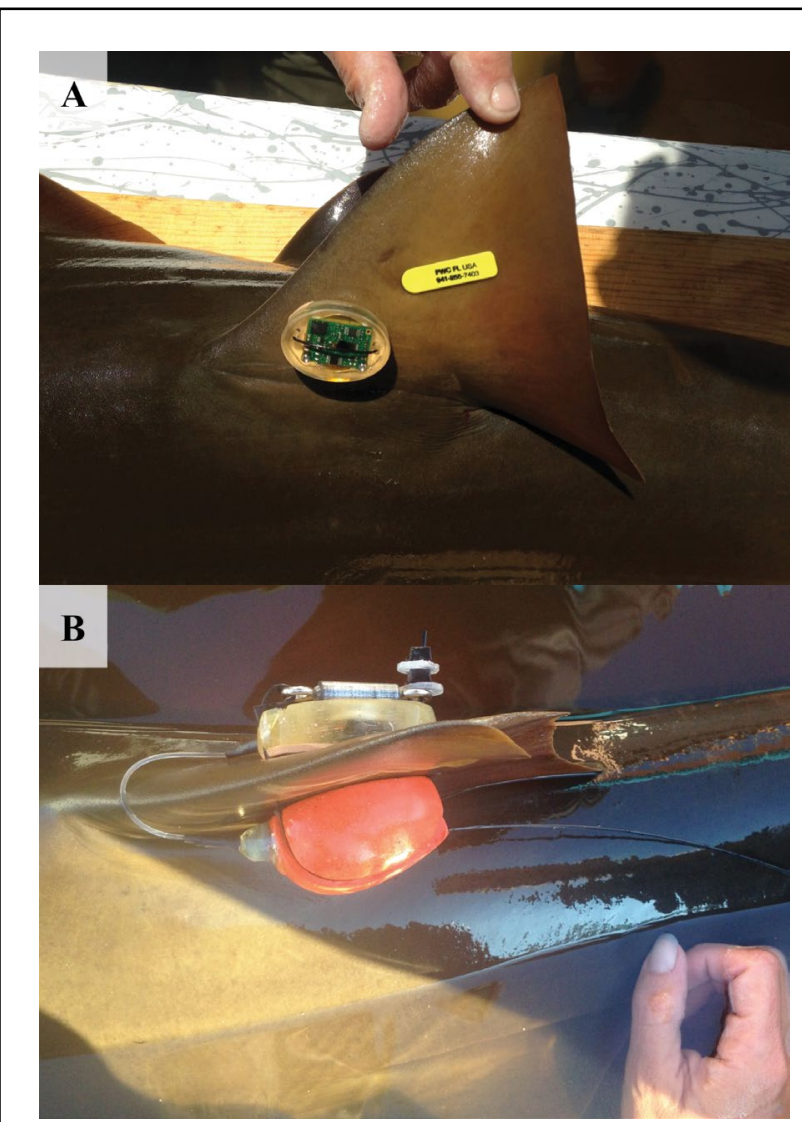

Figure 2

Photographs of acceleration data loggers (ADLs) attached to the first dorsal fins of 2 of the 10 smalltooth sawfish (Pristis pectinata) caught and tagged in the Peace River, Florida, from May 2014 through November 2015. (A) An ADL on an individual that was 1.7-m stretch total length (STL), paired with a continuous acoustic transmitter (not shown) to enable recapture and recovery of the logger. (B) A 1.8-m-STL individual, with the logger tethered to a float package that incorporated a very high frequency transmitter. A galvanic timed release was used to attach these float packages, allowing recovery of the $\mathrm{ADL}$ without recapture.

the 3 dynamic acceleration axes. We used ODBA to determine burst events, calculating the 98th percentile of ODBA for each individual by using means for each 1-s segment of data and subsequently classifying burst events as periods during which ODBA was continuously above this threshold for more than $3 \mathrm{~s}$ (Gleiss et al., 2017).

Because of permitting restrictions, no validation (groundtruthing) trials were run for this species to specifically link behaviors to their corresponding acceleration traces; however, ground-truthing has been conducted for the largetooth sawfish (Pristis pristis) (senior author and A. Gleiss, unpubl. data), as well as for the lemon shark (Negaprion brevirostris) (Brewster et al., 2018). These studies established that chafe behavior (dorsal rubbing) is defined by a distinctive $W$-shaped trace in the heave acceleration axis. Therefore, burst events with similar distinctive $W$-shaped 
traces (Fig. 3A) were removed from the burst event mask for each individual, leaving only burst events designated by large-amplitude and high-frequency lateral body movements for further analysis (Fig. 3, B and C). Mean depth, mean temperature, percentage of time spent active, and total number of burst events were summarized for each hour of the deployment for each individual.

Generalized additive mixed models (GAMMs) were built by using the mcgv package (vers. 1.8-28; Wood et al., 2017) in $\mathrm{R}$, vers. 3.5.2 ( $\mathrm{R}$ Core Team, 2018), and were used to analyze patterns in activity and bursting with respect to 5 fixed effects: depth, temperature, time of day, tide, and age class. Tidal period was split into 6 discrete phases-high, low, first ebb, second ebb, first flood, and second flood-by using tide data reported by NOAA's National Ocean Service for the Peace River (available from the Tides and Currents website). Periods of low and high tide were designated as the $2 \mathrm{~h}$ surrounding the minimum and maximum tide height within a cycle, and each bridging ebb and flood period was evenly divided into a first and second phase, with each tidal phase lasting approximately $2 \mathrm{~h}$. Smalltooth sawfish were split by age class into either a group for young of the year (YOY; <1.5 m STL) or a group for individuals age 1 or older ( $\geq 1.5 \mathrm{~m}$ STL) (Scharer et al., 2012), with 4 individuals in each group (Table 1 ).

To determine informative drivers of activity, a series of GAMMs were built for predicting the percentage of time sawfish were active by using different combinations and interactions of the 5 fixed effects. The Akaike information criterion corrected for small sample sizes (AICc) and log likelihood of each model were used to determine the best-fit model and the predictors that should be maintained in the model. The number of burst events observed in each hour was highly zero inflated; therefore, to describe patterns in burst events, a 2-step process was used following methods described by Gleiss et al. (2017). First, a series of GAMMs with binomial distributions was built to determine which fixed effects affected the probability of a burst event. Similar to what was done for the model for activity, the fit of different combinations of these predictor variables was assessed by using AICc, and the model

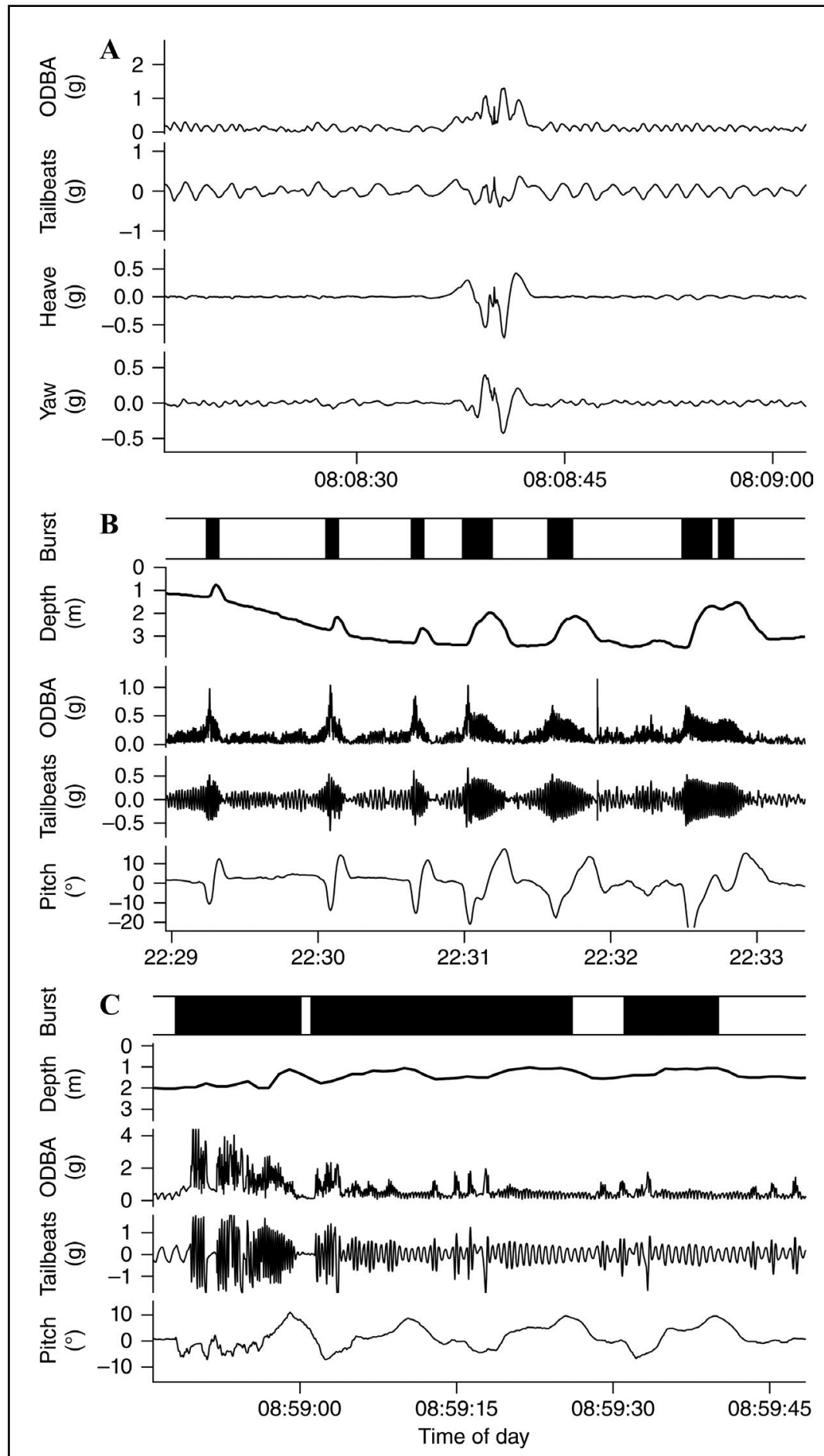

Figure 3

(A) Dynamic acceleration traces and overall dynamic body acceleration (ODBA) data that show a typical chafe event (dorsal rubbing) for the smalltooth sawfish (Pristis pectinata), characterized by a distinctive $W$ shape in the heave acceleration axis. These events were excluded from the burst event mask for each individual. Burst events included in the mask were generally characterized by either $(\mathbf{B})$ short bursts accompanied by sharp ascents or $(\mathbf{C})$ longer bursts without distinct changes in depth. Data used in these graphs were collected from acceleration data loggers deployed on smalltooth sawfish caught and tagged in the Peace River, Florida, between May 2014 and November 2015. 


\section{Table 1}

Details for the 8 recovered acceleration data loggers (ADLs) and the smalltooth sawfish (Pristis pectinata) on which they were deployed between May 2014 and November 2015 in the Peace River, Florida. Individuals were classified as either young of the year (YOY) or individuals age 1 or older, on the basis of stretch total length (Scharer et al., 2012). In this study, ADLs were attached either directly to the first dorsal fin, requiring recapture for retrieval, or were tethered to pop-off float packages that were retrieved while floating on the surface by using a very high frequency transmitter signal (Fig. 2). The asterisks (*) indicate the same individual caught 5 months after it was initially tagged. M=male; F=female.

\begin{tabular}{|c|c|c|c|c|c|c|}
\hline Sawfish ID & Date tagged & Sex & $\begin{array}{l}\text { Length } \\
(\mathrm{mm})\end{array}$ & Age class & $\begin{array}{l}\text { Deployment } \\
\text { duration }(\mathrm{d})\end{array}$ & $\begin{array}{c}\text { Retrieval } \\
\text { method }\end{array}$ \\
\hline 1 & 9 May 2014 & M & 808 & YOY & 5.03 & Recapture \\
\hline 2 & 12 Jun 2014 & M & 1735 & zage 1 & 5.37 & Recapture \\
\hline 3 & 12 Jun 2014 & $\mathrm{~F}$ & 1575 & zage 1 & 5.09 & Recapture \\
\hline 4 & 11 Jun 2015 & M & 980 & YOY & 5.06 & Recapture \\
\hline $5^{*}$ & 11 Jun 2015 & $\mathrm{~F}$ & 1025 & YOY & 5.13 & Recapture \\
\hline 6 & 11 Jun 2015 & $\mathrm{~F}$ & 1049 & YOY & 5.12 & Recapture \\
\hline 7 & 10 Nov 2015 & $\mathrm{~F}$ & 1831 & zage 1 & 5.23 & Pop-off \\
\hline $8^{*}$ & 20 Nov 2015 & $\mathrm{~F}$ & 1531 & zage 1 & 5.42 & Pop-off \\
\hline
\end{tabular}

with the lowest AICc was determined to have the best fit. Following the formation of this model describing the burst probability, the hours during which no burst events were detected were removed from the analysis, and the number of bursts observed in the remaining hours was modeled by using a GAMM with a negative binomial distribution. This model included the same predictor variables used in the previously described models, and the best-fit combination of fixed-effect predictor variables was determined by using AICc.

In all GAMMs, normality of residuals was confirmed by using the gam.check function in the mcgv package in $\mathrm{R}$, and autocorrelation was accounted for by using the CorAR1 function. Cyclic smoothers were used for time of day to reflect the circular nature of the 24-h clock. Fixed effects that were maintained in the chosen model were further examined with Tukey's honestly significant difference (HSD) tests by using the multcomp package, vers. 1.4-10 (Hothorn et al., 2008). Additionally, to determine whether there was a shift in depth distributions with size, the frequency distributions of hourly depths of YOY and individuals age 1 or older were compared by using a Kolmogorov-Smirnov test.

\section{Data processing and analyses: passive acoustic monitoring}

Acoustic transmitter data were downloaded from acoustic receivers and examined to provide location data concurrent with ADL-derived behavioral data. Positions derived from acoustic data were matched with those from $\mathrm{ADL}$ data by using time stamps, and a location was designated for each hour that acoustic transmissions were received. Receivers were deployed in 2 habitats: creeks, lined with red mangroves (Rhizophora mangle), that are generally shallow, enclosed habitats (with depths $<1 \mathrm{~m}$ at most tides) and habitats within the main stem (or main channel) of the Peace River that are generally deeper (with depths of 1-3 m at most tides), more open areas with less habitat complexity (Fig. 1). If acoustic transmissions were received from multiple habitats during the same hour of deployment or if they were not received during an hour of deployment, data were not included in location analyses. The percentage of time smalltooth sawfish were active and the probability and frequency of burst events were compared between the 2 types of habitats by using analysis of variance (ANOVA), with depth, temperature, time of day, tide, and age class included as fixed-effect predictors in the models and individual included as a random effect. The dredge function in the MuMIn package (vers. 0.12.0; Bartoń, 2009) in $\mathrm{R}$ was used to determine which factors should be included as informative predictors of activity and burst events.

To visualize the overall area and habitat use by smalltooth sawfish while they carried ADLs, a contour map was created by using Surfer 13 (Golden Software LLC, Golden, CO) following the methods of Huston et al. (2017). Age classes were combined because all individuals used the same area of the river regardless of size during the 5-d ADL deployments.

\section{Results}

Between May 2014 and November 2015, ADLs were deployed on 10 smalltooth sawfish (Table 1). Eight of these tags were recovered, and over $994 \mathrm{~h}$ of high-resolution behavioral data were collected from them (Fig. 4). Acoustic detections were received during $225 \mathrm{~h}$ of the ADL deployments, providing concurrent position and behavior data for these hours. Burst events were identified for all sawfish, with 6-58 burst events observed per day for individuals. These burst events composed 2 main categories: repeated, 


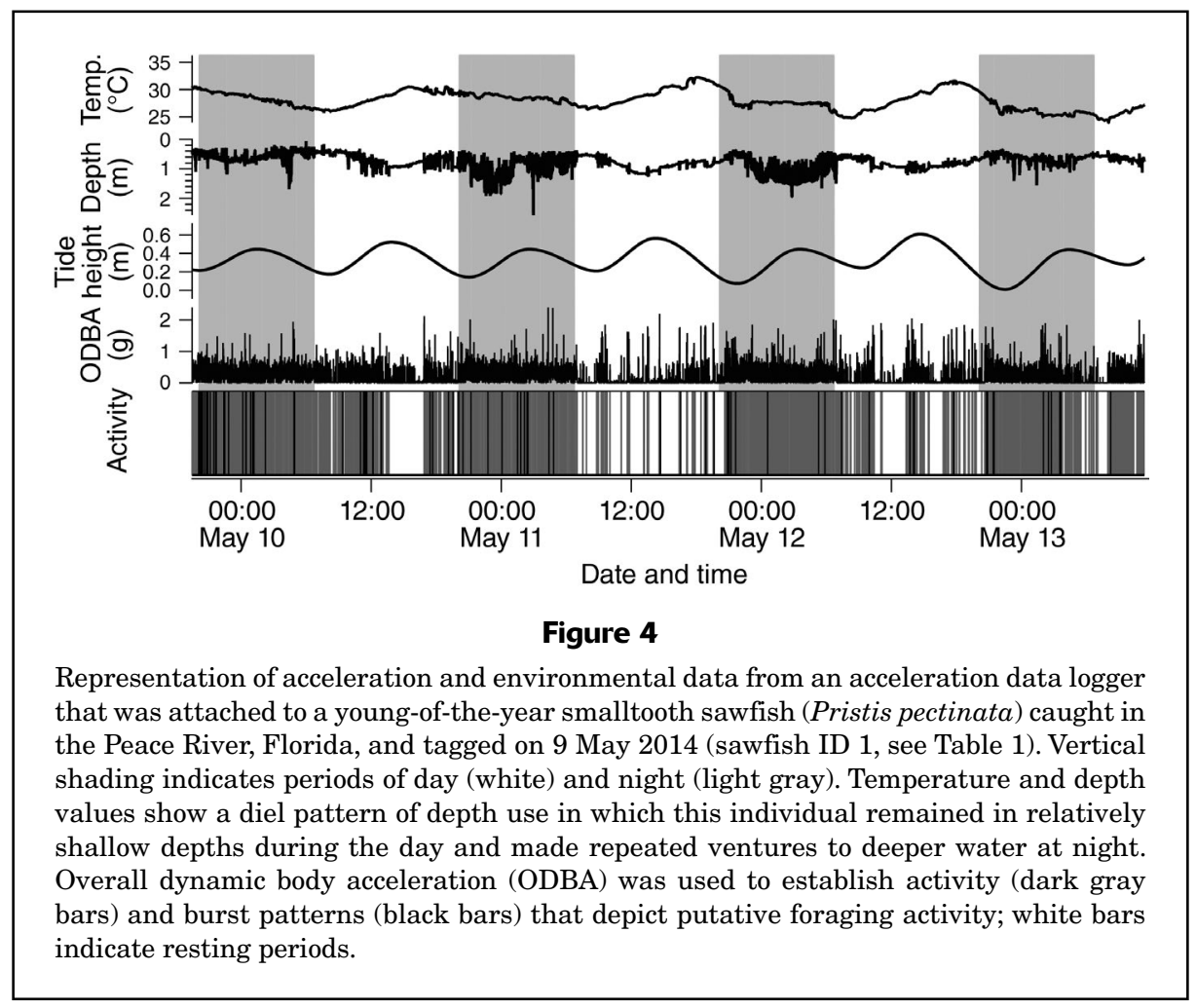

short (5-10 s) bursts accompanied by sharp ascents (Fig. 3B), accounting for approximately $24 \%$ of observed burst events, and bursts of variable duration up to $45 \mathrm{~s}$ without predictable changes in depth (Fig. 3C). Water temperatures during deployments were $24.5-32.7^{\circ} \mathrm{C}$ for sawfish tagged in May and June and $20.6-28.9^{\circ} \mathrm{C}$ for individuals tagged in November.

The model that best described activity included depth, temperature, time of day, and tide as fixed-effect predictors (Table 2). Smalltooth sawfish were significantly more active during the evening and night hours, with a peak in activity around 2200, a few hours after typical sunset, and a second smaller peak around 0500, near sunrise (Fig. 5). Activity increased with temperature. Individuals were also more active at depths around $0.8 \mathrm{~m}$ (Fig. 5), with decreased activity in shallower and deeper areas, and were more active during the lower half of the tidal cycle (i.e., second ebb, low tide, and first flood) than during the higher half of the tidal cycle (i.e., second flood, high tide, and first ebb) (Tukey's HSD: $P<0.05$; Fig. 5). Hourly mean depth of sawfish was significantly shallower at low tide (mean: $0.57 \mathrm{~m}$ [standard error (SE) 0.04]) than at high tide (mean: $0.75 \mathrm{~m}$ [SE 0.04]) (ANOVA: $P<0.001$, $\mathrm{df}=1$, $F=11.94$ ), although there was no difference in mean depth between day and night (ANOVA: $P>0.05, \mathrm{df}=1, F=2.40$ ).

The best-fit model describing the probability of a burst event included only age class as a predictor, with bursts more likely to occur in YOY smalltooth sawfish than in individuals age 1 or older. However, time of day was the most important predictor of burst frequency and the only predictor maintained in the best-fit model (Table 2). This result indicates that, although the likelihood that bursts would occur was the same for all hours of the day, the burst frequency increased substantially during evening and night hours, with the highest burst frequency observed around 2200, coinciding with the peak in percentage of time sawfish were active.

The distributions of the recorded depths of YOY and individuals age 1 and older were significantly different (Kolmogorov-Smirnov test: $P<0.0001)$. An overall mean depth of $0.5 \mathrm{~m}$ was observed for YOY, with an hourly mean depth range of 0.1-1.5 m. Larger individuals (age 1 or older) made occasional excursions into deeper water, with an overall mean depth of $0.8 \mathrm{~m}$ and an hourly mean depth range of $0.2-3.6 \mathrm{~m}$ (Fig. 6).

Although acoustic tags were concurrently deployed with ADLs on all smalltooth sawfish, detections were sparse for some individuals during ADL deployments, with location categorized in $226 \mathrm{~h}$ of ADL deployments (126 h in the main stem of the Peace River and $100 \mathrm{~h}$ in mangrove creek habitats). This lack of detections for some fish made it difficult to link specific locations with behaviors, but data were sufficient to compare behaviors between broad habitat categories. Habitat type was an informative predictor of activity, along with tidal period and depth, with individuals more active in the main channel than in mangrove creek habitats (Tukey's HSD: $P<0.05$; Fig. 7). Habitat type was also an informative predictor of burst frequency, along with tide and depth, and of the burst probability, along with tide, depth, and age class. Smalltooth 


\section{Table 2}

The top-5 combinations of fixed effects in generalized additive mixed models used to predict 1) the percentage of time smalltooth sawfish (Pristis pectinata) were active (Activity), 2) burst probability, and 3) burst frequency. Degrees of freedom (df), log likelihood (logLik), and the corrected Aikake's information criterion (AICc) were used to determine the best-fit models, which are indicated with asterisks. The burst frequency model described by only hour of day (HOD) was selected as the most parsimonious model, with relative differences between AICc values $(\triangle \mathrm{AICc})<2$ for the top model. All models included individual as a random effect. Data used in the models were collected during deployments of acceleration data loggers in the Peace River, Florida, between May 2014 and November 2015.

\begin{tabular}{|c|c|c|c|c|}
\hline Model & $\mathrm{df}$ & $\operatorname{logLik}$ & $\mathrm{AICc}$ & $\triangle \mathrm{AICc}$ \\
\hline \multicolumn{5}{|l|}{ Activity } \\
\hline$\sim$ HOD + Temp + Depth + Tide* & 13 & -4068.5 & 8137.0 & \\
\hline$\sim$ HOD + Temp + Depth + Tide + Age class & 14 & -4068.1 & 8137.9 & 1.2 \\
\hline$\sim$ HOD + Temp + Tide & 11 & -4072.8 & 8140.9 & 4.5 \\
\hline$\sim \mathrm{HOD}+\mathrm{Temp}$ & 6 & -4082.2 & 8150.3 & 13.4 \\
\hline$\sim \mathrm{HOD}+$ Temp + Age class & 7 & -4082.1 & 8150.9 & 17.5 \\
\hline \multicolumn{5}{|l|}{ Burst probability } \\
\hline Age class* & 3 & -1914.6 & 3835.3 & \\
\hline$\sim$ Depth & 4 & -1915.9 & 3839.7 & 4.4 \\
\hline$\sim$ Depth + Age class & 5 & -1915.2 & 3840.4 & 5.1 \\
\hline Tide & 7 & -1916.0 & 3845.9 & 10.6 \\
\hline$\sim$ Tide + Age class & 8 & -1915.2 & 3846.4 & 11.1 \\
\hline \multicolumn{5}{|l|}{ Burst frequency } \\
\hline$\sim$ HOD + Age class & 5 & -1021.6 & 2053.2 & \\
\hline$\sim \mathrm{HOD}^{*}$ & 4 & -1022.8 & 2053.6 & 0.4 \\
\hline$\sim \mathrm{HOD}+$ Tide & 9 & -1018.0 & 2053.9 & 0.7 \\
\hline$\sim \mathrm{HOD}+$ Depth + Age class & 7 & -1020.3 & 2054.6 & 1.4 \\
\hline$\sim$ HOD + Depth + Tide + Age class & 12 & -1015.5 & 2054.9 & 1.7 \\
\hline
\end{tabular}

sawfish were more likely to burst in the main stem of the river than in mangrove creek habitats (Tukey's HSD: $P<0.05$; Fig. 7), and a greater burst frequency was observed in the main channel; however, this difference was not significant (Tukey's HSD: $P>0.05$; Fig. 7 ).

Smalltooth sawfish that were fitted with ADLs remained in a small portion of the Peace River (Figs. 1 and 7). Both size classes remained in enclosed creek habitats during the day and in more open habitats in the main stem of the river at night.

\section{Discussion}

This study, the first to deploy ADLs on smalltooth sawfish, provides behavioral data that describes their finescale activity and behavior patterns, including potential foraging strategies. Acceleration data indicate that a number of factors, including time of day, tidal period, depth, age class, and habitat, affect activity and foraging rates in this species. These data will increase our understanding of how this critically endangered species behaves in its nursery habitats throughout juvenile life stages and will assist in management and conservation of crucial nursery areas.

\section{Purported foraging behavior}

Foraging behavior of sawfish species is seldom observed in natural habitats and is generally not well documented, although the toothed rostrum is known to aid in stunning and pinning prey as well as in electroreception (Wueringer et al., 2011, 2012). Because validation trials could not be performed to match acceleration traces with specific behaviors in our study, it was impossible to identify foraging activity with certainty from the acceleration data we collected (Whitney et al., 2018). However, by examining video footage of feeding sawfish in captivity (Wueringer et al., 2011, 2012), and by considering the results of ground-truthing trials for data collected on acceleration behavior of the largetooth sawfish (senior author and A. Gleiss, unpubl. data), we made some deductions about the relation of the burst events observed in our study to putative foraging activity. Conservatively, it is likely that any foraging activity displayed by ADL-tagged smalltooth sawfish was included in the 98th percentile burst event mask determined for each fish, although bursts tied to predator escape or startle responses may also be included in this subset of data.

Many of the burst events we recorded were accompanied by acute ascents (see Fig. 3B), indicating that smalltooth 


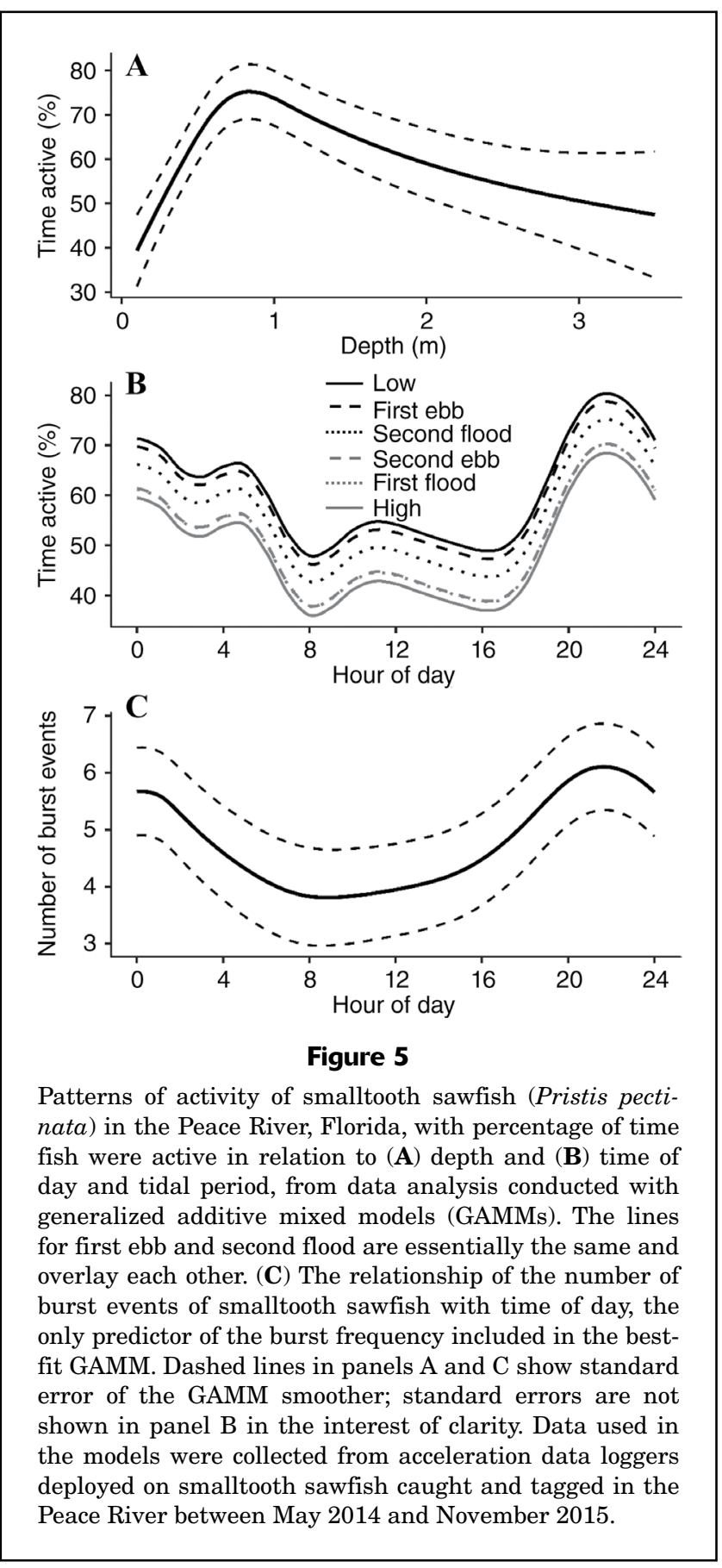

sawfish may travel or wait near the bottom and quickly burst upward into the water column, potentially in pursuit of teleost fishes, their primary prey (Poulakis et al., 2017). Other burst events were not accompanied by predictable changes in depth, instead occurring at relatively constant depths, presumably on or near the bottom. We hypothesize that these events indicate benthic prey capture or pinning behavior, in which smalltooth sawfish pin prey, such as rays, on the substrate (Poulakis et al., 2017), using their rostrum until they can maneuver prey into their mouths (Wueringer et al., 2012). These high-acceleration amplitude

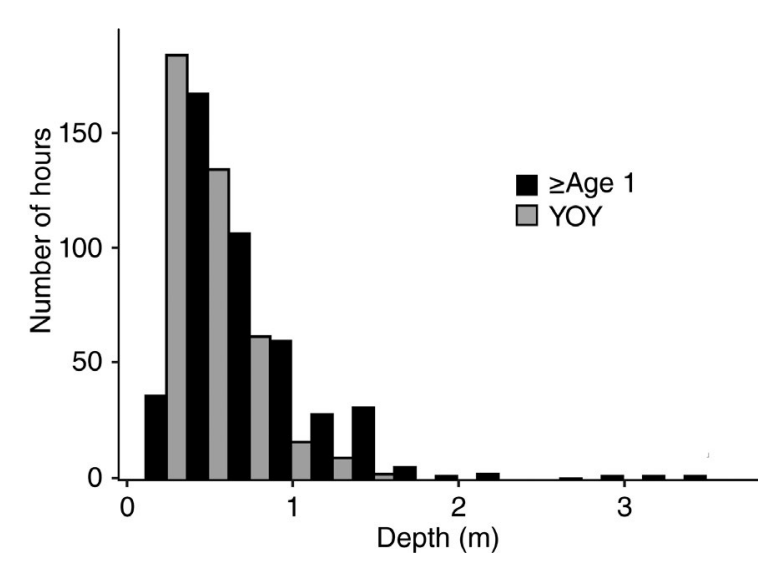

Figure 6

Frequency of use of depths by smalltooth sawfish (Pristis pectinata), by age class, in the Peace River, Florida, from May 2014 through November 2015. Depth values are mean depths (in paired bins of $0.25 \mathrm{~m}$ ) from all hours of deployment of acceleration data loggers. The age classes were young of the year (YOY, $<1.5 \mathrm{~m}$ stretch total length [STL]) and individuals $\geq$ age 1 ( $\geq 1.5 \mathrm{~m} \mathrm{STL})$. The youngest individuals used shallower depths than those used by older individuals, and they did not occur below $1.5 \mathrm{~m}$; older individuals made occasional excusions up to $3.6 \mathrm{~m}$.

signals could also represent sawfish avoiding predation by bull sharks (Carcharhinus leucas), which are one of the main predators of smalltooth sawfish in Florida (Brame et al., 2019). However, predation pressure on smalltooth sawfish in the Peace River is considered low because of the divergent salinity affinities between bull sharks and smalltooth sawfish (Poulakis et al., 2011).

\section{Environmental drivers of activity and foraging}

Temperature and time of day were the most influential drivers of activity, with both factors included in the top- 5 candidate models for activity. The highest activity rates were observed at higher water temperatures and during evening and night hours. That activity increased with water temperature was not unexpected because ectothermic animals, including elasmobranchs, often increase activity as temperatures increase and, therefore, muscle performance capacity and metabolic needs increase (Halsey et al., 2015; Lear et al., 2017, 2019). The crepuscular and nocturnal activity observed in the smalltooth sawfish is also similar to that observed in many elasmobranchs (reviewed by Hammerschlag et al., 2017), activity that is often attributed to the exceptional sensory capabilities of elasmobranchs (Hueter et al., 2004).

Similar crepuscular and nocturnal activity has been observed in other sawfish species (Gleiss et al., 2017; Whitty et al., 2017), and these findings confirm hypotheses of diel activity patterns in juvenile smalltooth sawfish formed during previous studies that included passive and active acoustic monitoring (Hollensead et al., 2016; 


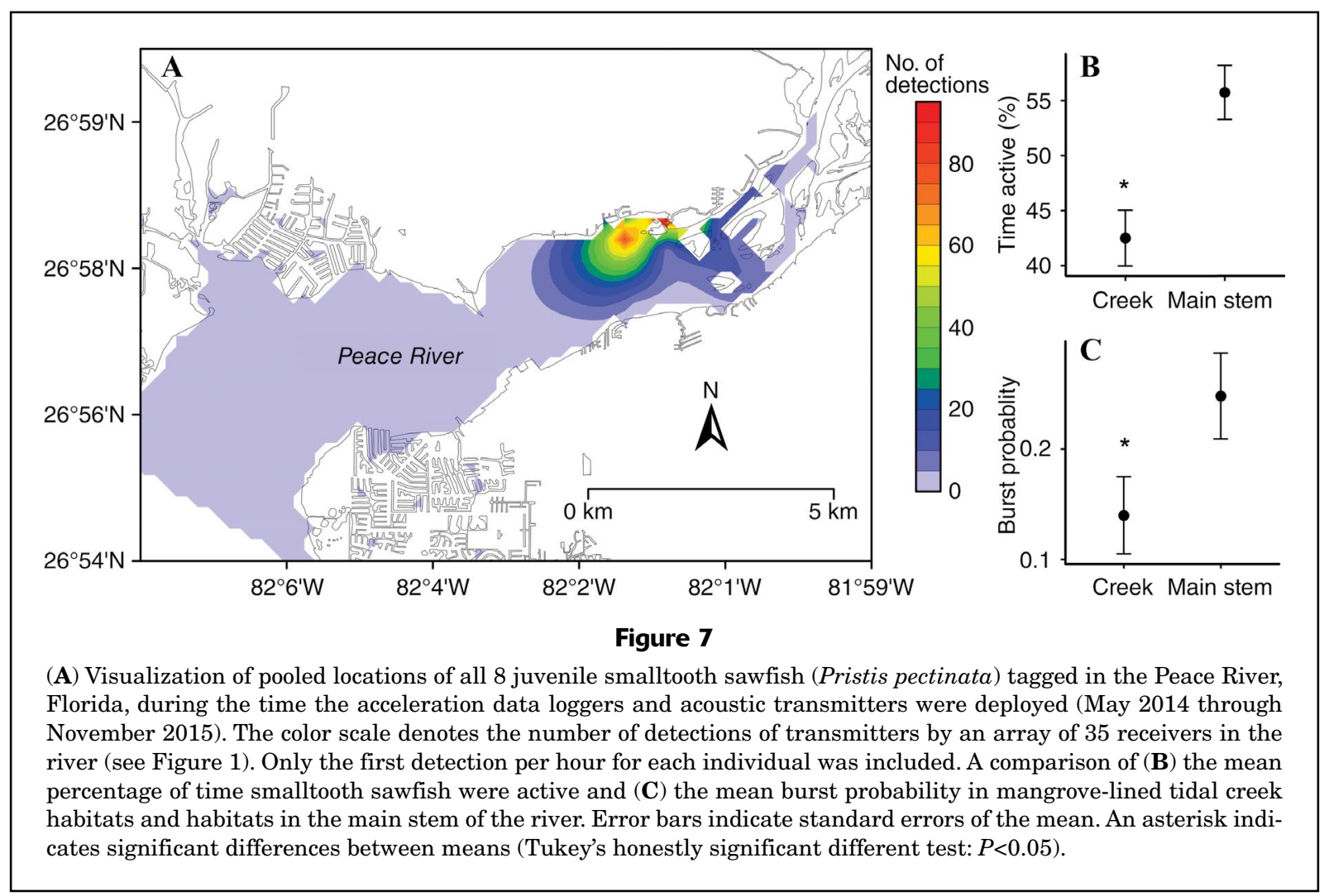

Huston et al., 2017; Scharer et al., 2017). The results of these previous studies indicate that juveniles rest in shallow creeks during the day and are active in the main channel of a river at night. Although data from the use of these monitoring techniques describe horizontal movements, it can be difficult to use acoustic data to accurately assess activity levels because movements are recorded during passive acoustic monitoring only when sawfish travel between receivers, not when they travel within the area covered by an individual receiver. In our study, data from ADLs directly confirmed these diel patterns.

In addition to time of day and temperature, depth and tide also significantly affected activity. Smalltooth sawfish were more active in the middle range of depths observed during ADL deployments and in the lower half of the tidal cycle. Decreased activity in the shallowest depths likely reflects sawfish refuging in the shallowest habitats. The decrease in activity at depths $>1 \mathrm{~m}$ by fish could be a method of predator avoidance, given that bull sharks are more common in these deeper areas (Heupel et al., 2010), or it could indicate a lie-in-wait hunting strategy in deeper water. Alternatively, smalltooth sawfish could use deeper areas only for transiting through different habitats, as suggested by May et al. (2019), and could forage more actively in relatively shallow habitats of approximately $1 \mathrm{~m}$. The relationship between activity levels and tidal stage observed in our study has not been indicated by results of previous studies (e.g., Hollensead et al., 2016). In our study, increased activity at lower tide heights could have been due to lower refuging potential at low tide because some shallow mangrove habitats that sawfish use as refuges may not be available at low tide (Simpfendorfer et al., 2010), forcing individuals to leave refuge locations and become more active as the tide drops. This pattern emerged despite a relatively small daily change in tide height, with daily tidal variance $<1 \mathrm{~m}$.

Time of day was also an important predictor of burst activity, with the greatest number of burst events observed during evening and night hours. However, although individuals generally adhered to these patterns, some foraging events also occurred during the day, timing that has been confirmed by using baited-rod-and-reel-derived public encounter data (Poulakis and Seitz, 2004), indicating that smalltooth sawfish opportunistically feed during the day and at night. Time of day was the only factor included in the final model describing burst frequency; however, burst probability was best described by age class, with YOY more likely to burst than individuals age 1 or older. Smalltooth sawfish are known to double in length by the end of their first year (Scharer et al., 2012); therefore, YOY may need to feed more often, on smaller prey items, than older individuals to achieve these growth rates. In addition, YOY individuals could be less experienced feeders and are under higher predation pressure in comparison with individuals age 1 or older. As a result, there may be more unsuccessful feeding attempts and a higher frequency of predator escape behavior (or startle responses) in YOY fish, contributing to their higher rate of burst activities.

In addition to differences in burst activity between age classes, there were also significant differences between the 
depth distributions of YOY and older fish, with fish age 1 and older venturing deeper than YOY. This ontogenetic shift in depth use has been reported in a number of previous studies of both smalltooth and largetooth sawfish, indicating that YOY individuals stayed in shallow areas close to shore while larger fish that have less predation risk ventured farther from shorelines to use deeper habitats (Whitty et al., 2009; Simpfendorfer et al., 2010; Huston et al., 2017).

\section{Habitat use and foraging ecology}

The patterns of activity and putative foraging effort, combined with knowledge about depth and habitat use, reveal important insights into the foraging ecology of these animals. Increased activity and putative foraging of smalltooth sawfish was tied to habitats in the main stem of the Peace River, and refuging was more common in shallow habitats. This pattern is the opposite of that observed in the morphologically similar largetooth sawfish (Gleiss et al., 2017; Whitty et al., 2017). Largetooth sawfish studied in the Fitzroy River, Australia, are thought to use shallow sandbar habitats, which are generally devoid of woody debris, to forage because of increased abundance of prey, and snags and woody debris in the deeper areas of the river offer better refuging habitats from crocodilians, which are common along shorelines (Morgan et al., 2017; Whitty et al., 2017). Although foraging in shallow habitats could be similarly beneficial for smalltooth sawfish, some shallow habitats in the Peace River, such as red-mangrovelined tidal creeks, have increased habitat complexity and are spatially restricted, possibly limiting overall foraging success. Moving away from these shallow habitats into the slightly deeper main channel at night may improve foraging success in the Peace River, and the shallow mangrove creeks and shorelines may provide more of a protection function from bull sharks; these habitats are known to be used as refuging areas in multiple nurseries in Florida (Simpfendorfer et al., 2010; Poulakis et al., 2013, 2016). Shallow creek habitats in the Peace River may offer protection from boat traffic and noise as well as from predators.

A similar diel pattern in habitat use has been reported from passive acoustic monitoring conducted over many years in the Peace River (Huston et al., 2017; Scharer et al., 2017; May et al., 2019), as well as from active and passive acoustic tracking conducted in other Florida nurseries (Simpfendorfer et al., 2010, 2011; Poulakis et al., 2013, 2016; Hollensead et al., 2016). All of these studies confirm that juvenile smalltooth sawfish refuge during the day in protected creek habitats, especially those lined with red mangroves (Norton et al., 2012). Although the authors of some of these studies have proposed that smalltooth sawfish use deeper habitats to forage because of increased nighttime detections by receivers in main channels (e.g., Poulakis et al., 2016; Huston et al., 2017), the use of alternative shallow nighttime foraging grounds has been observed in other studies. For example, May et al. (2019) found that, although smalltooth sawfish in the Peace River crossed the deeper main stem of the river at night, they did so in large part to use shallow habitats that included oyster reefs on the shoreline opposite to their protected daytime refuge. Shallow mud flats and habitats within the main river channel have also been reported as possible nighttime foraging areas for smalltooth sawfish in different Florida nurseries (Hollensead et al., 2016; Poulakis et al., 2016). Therefore, food availability and acquisition success may play roles in influencing where juveniles forage. For example, juveniles may forage in or near refuge locations when sufficient prey is available but venture farther into or across the main stem of the river if there is not sufficient prey or if densities of conspecifics near refuge locations are too high.

In our study, burst events were recorded at depths ranging from 0.1 to $3.6 \mathrm{~m}$, indicating that a variety of habitats are important foraging areas for this species. However, regardless of foraging location, the timing of heightened activity and foraging appears to be maintained across nursery habitats and populations, given that all previous studies have found heightened activity at night in the Peace River and other nurseries (Poulakis et al., 2013, 2016; Hollensead et al., 2016; Huston et al., 2017; Scharer et al., 2017; May et al., 2019).

\section{Conservation implications and future directions}

This new information that relates putative foraging activity to habitat use has improved our understanding of the early life history of the smalltooth sawfish and validated previous hypotheses about activity patterns developed through acoustic monitoring studies. Increasing ADL deployment times and deploying ADLs throughout the year in future studies would help to identify long-term foraging and activity patterns, particularly in association with seasonal changes in abiotic variables, such as temperature and salinity. Additionally, deploying ADLs concurrently with a tracking system that can detect movements on a scale as small as meters, such as a Vemco Positioning System, would help to determine habitat use on a fine scale by enabling the matching of behaviors to specific sites within a nursery. Finally, conducting laboratory trials for validation of acceleration signals of smalltooth sawfish or deploying video cameras concurrently with ADLs in the field would help to conclusively determine feeding and other behaviors.

Even with its limitations, the information describing habitat use and potential foraging strategies provided by this study is valuable for understanding the habitat requirements of this species and emphasizes the importance of preserving a variety of habitats, including mangrove-lined creeks used by smalltooth sawfish as refuging areas and less complex habitats used as foraging grounds within nurseries. This information will help to guide crucial management and conservation efforts for the smalltooth sawfish in the Peace River and throughout the range of this species.

\section{Acknowledgments}

This research was supported by funding from the National Marine Fisheries Service (grant NA13NMF4720047) under 
Section 6 of the U.S. Endangered Species Act (Cooperation with the States) and from Mote Marine Laboratory. We thank the staff at the Charlotte Harbor Field Laboratory, Florida Fish and Wildlife Conservation Commission, for assistance with capturing and tagging smalltooth sawfish. The senior author was supported by the Forrest Research Foundation and an Australian Government Research Training Program Scholarship.

\section{Literature cited}

Bartoń, K.

2009. MuMIn: multi-model inference. $\mathrm{R}$ package, vers. 0.12.0. [Available from website, accessed January 2018.]

Bigelow, H. B., and W. C. Schroeder.

1953. Fishes of the western North Atlantic, part 2: sawfishes, guitarfishes, skates, rays and chimaeroids, 514 p. Yale Univ., New Haven, CT.

Brame, A. B., T. R. Wiley, J. K. Carlson, S. V. Fordham, R. D. Grubbs, J. Osborne, R. M. Scharer, D. M. Bethea, and G. R. Poulakis.

2019. Biology, ecology, and status of the smalltooth sawfish Pristis pectinata in the USA. Endanger. Species Res. 39:9-23. Crossref

Brewster, L. R., J. J. Dale, T. L. Guttridge, S. H. Gruber, A. C. Hansell, M. Elliott, I. G. Cowx, N. M. Whitney, and A. C. Gleiss.

2018. Development and application of a machine learning algorithm for classification of elasmobranch behaviour from accelerometry data. Mar. Biol. 165:62. Crossref

Carlson, J., T. Wiley, and K. Smith. 2013. Pristis pectinata (errata version published in 2019). The IUCN Red List of Threatened Species 2013: e.T18175A141791261. [Available from website.]

Dulvy, N. K., S. L. Fowler, J. A. Musick, R. D. Cavanagh, P. M. Kyne,

L. R. Harrison, J. K. Carlson, L. N. K. Davidson, S. V. Fordham,

M. P. Francis, et al.

2014. Extinction risk and conservation of the world's sharks and rays. eLife 3:e00590. Crossref

Dulvy, N. K., L. N. K. Davidson, P. M. Kyne, C. A. Simpfendorfer,

L. R. Harrison, J. K. Carlson, and S. V. Fordham.

2016. Ghosts of the coast: global extinction risk and conservation of sawfishes. Aquat. Conserv. 26:134-153. Crossref

Federal Register.

2003. Endangered and threatened species; final endangered status for a distinct population segment of smalltooth sawfish (Pristis pectinata) in the United States. Fed. Regist. 68:15674-15680. [Available from website.]

Gleiss, A. C., R. P. Wilson, and E. L. C. Shepard.

2011. Making overall dynamic body acceleration work: on the theory of acceleration as a proxy for energy expenditure. Methods Ecol. Evol. 2:23-33. Crossref

Gleiss, A. C., D. L. Morgan, J. M. Whitty, J. J. Keleher, S. Fossette, and G. C. Hays.

2017. Are vertical migrations driven by circadian behaviour? Decoupling of activity and depth use in a large riverine elasmobranch, the freshwater sawfish (Pristis pristis). Hydrobiologia 787:181-191. Crossref

Halsey, L. G., P. G. D. Matthews, E. L. Rezende, L. Chauvaud, and A. A. Robson.

2015. The interactions between temperature and activity levels in driving metabolic rate: theory, with empirical validation from contrasting ectotherms. Oecologia 177:11171129. Crossref
Hammerschlag, N., R. A. Skubel, H. Calich, E. R. Nelson, D. S. Shiffman, J. Wester, C. C. Macdonald, S. Cain, L. Jennings, A. Enchelmaier, et al.

2017. Nocturnal and crepuscular behavior in elasmobranchs: a review of movement, habitat use, foraging, and reproduction in the dark. Bull. Mar. Sci. 93:355-374.

Heupel, M. R., B. G. Yeiser, A. B. Collins, L. Ortega, and C. A. Simpfendorfer.

2010. Long-term presence and movement patterns of juvenile bull sharks, Carcharhinus leucas, in an estuarine river system. Mar. Freshw. Res. 61:1-10. Crossref

Hollensead, L. D., R. D. Grubbs, J. K. Carlson, and D. M. Bethea. 2016. Analysis of fine-scale daily movement patterns of juvenile Pristis pectinata within a nursery habitat. Aquat. Conserv. 26:492-505. Crossref

Hothorn, T., F. Bretz, and P. Westfall.

2008. Simultaneous inference in general parametric models. Biomet. J. 50:346-363. Crossref

Hueter, R. E., D. A. Mann, K. P. Maruska, J. A. Sisneros, and L. S. Demski.

2004. Sensory biology of elasmobranchs. In Biology of sharks and their relatives (J. C. Carrier, J. A. Musick, and M. R. Heithaus, eds.), p. 325-368. CRC Press, Boca Raton, FL.

Huston, C. A., P. W. Stevens, R. M. Blaxton, S. G. Tolley, R. M. Scharer, B. M. Tornwall, and G. R. Poulakis.

2017. Diel movements of juvenile smalltooth sawfish: implications for defining the size of a nursery hotspot. Endanger. Species Res. 34:311-322. Crossref

Lear, K. O., and N. M. Whitney.

2016. Bringing data to the surface: recovering data loggers from large sample sizes in marine vertebrates. Anim. Biotelem. 4:12. Crossref

Lear, K. O., N. M. Whitney, L. R. Brewster, J. J. Morris, R. E. Hueter, and A. C. Gleiss.

2017. Correlations of metabolic rate and body acceleration in three species of coastal sharks under contrasting temperature regimes. J. Exp. Biol. 220:397-407. Crossref

Lear, K. O., N. M. Whitney, D. L. Morgan, L. R. Brewster, J. M. Whitty, G. R. Poulakis, R. M. Scharer, T. L. Guttridge, and A. C. Gleiss.

2019. Thermal performance responses in free-ranging elasmobranchs depend on habitat use and body size. Oecologia 191:829-842. Crossref

May, R. K., S. G. Tolley, R. M. Scharer, B. Dye, F. Jose, and G. R. Poulakis.

2019. Automated monitoring of fine-scale movements of the endangered smalltooth sawfish (Pristis pectinata). Fish. Bull. 117:360-371. Crossref

Morgan, D. L., R. Somaweera, A. C. Gleiss, S. J. Beatty, and J. M. Whitty.

2017. An upstream migration fought with danger: freshwater sawfish fending off sharks and crocodiles. Ecology 98:1465-1467. Crossref

Norton, S. L., T. R. Wiley, J. K. Carlson, A. L. Frick, G. R. Poulakis, and C. A. Simpfendorfer.

2012. Designating critical habitat for juvenile endangered smalltooth sawfish in the United States. Mar. Coast. Fish. 4:473-480. Crossref

Poulakis, G. R., and J. C. Seitz.

2004. Recent occurrence of the smalltooth sawfish, Pristis pectinata (Elasmobranchiomorphi: Pristidae), in Florida Bay and the Florida Keys, with comments on sawfish ecology. Fla. Sci. 67:27-35.

Poulakis, G. R., and R. D. Grubbs.

2019. Biology and ecology of sawfishes: global status of research and future outlook. Endanger. Species Res. 39:77-90. Crossref 
Poulakis, G. R., P. W. Stevens, A. A. Timmers, T. R. Wiley, and C. A. Simpfendorfer.

2011. Abiotic affinities and spatiotemporal distribution of the endangered smalltooth sawfish, Pristis pectinata, in a south-western Florida nursery. Mar. Freshw. Res. 62:1165-1177. Crossref

Poulakis, G. R., P. W. Stevens, A. A. Timmers, C. J. Stafford, and

C. A. Simpfendorfer.

2013. Movements of juvenile endangered smalltooth sawfish, Pristis pectinata, in an estuarine river system: use of non-mainstem river habitats and lagged responses to freshwater inflowrelated changes. Environ. Biol. Fish. 96:763-778. Crossref

Poulakis, G. R., P. W. Stevens, A. A. Timmers, C. J. Stafford,

D. D. Chapman, K. A. Feldheim, M. R. Heupel, and C. Curtis.

2016. Long-term site fidelity of endangered smalltooth sawfish (Pristis pectinata) from different mothers. Fish. Bull. 114:461-475. Crossref

Poulakis, G. R., H. Urakawa, P. W. Stevens, J. A. DeAngelo,

A. A. Timmers, R. D. Grubbs, A. T. Fisk, and J. A. Olin.

2017. Sympatric elasmobranchs and fecal samples provide insight into the trophic ecology of the smalltooth sawfish. Endanger. Species Res. 32:491-506. Crossref

$\mathrm{R}$ Core Team.

2018. R: a language and environment for statistical computing. R Foundation for Statistical Computing, Vienna, Austria. [Available from website, accessed December 2018.]

Sakamoto, K. Q., K. Sato, M. Ishizuka, Y. Watanuki, A. Takahashi,

F. Daunt, and S. Wanless.

2009. Can ethograms be automatically generated using body acceleration data from free-ranging birds? PLoS ONE 4(4):e5379. Crossref

Scharer, R. M., W. F. Patterson III, J. K. Carlson, and G. R. Poulakis. 2012. Age and growth of endangered smalltooth sawfish (Pristis pectinata) verified with LA-ICP-MS analysis of vertebrae. PLoS ONE 7(10):e47850. Crossref

Scharer, R. M., P. W. Stevens, C. P. Shea, and G. R. Poulakis.

2017. All nurseries are not created equal: large-scale habitat use patterns in two smalltooth sawfish nurseries. Endanger. Species Res. 34:473-492. Crossref

Seitz, J. C., and G. R. Poulakis.

2006. Anthropogenic effects on the smalltooth sawfish (Pristis pectinata) in the United States. Mar. Pollut. Bull. 52:1533-1540. Crossref

Shepard, E. L. C., R. P. Wilson, L. G. Halsey, F. Quintana,

A. G. Laich, A. C. Gleiss, N. Liebsch, A. E. Myers, and B. Norman. 2008. Derivation of body motion via appropriate smoothing of acceleration data. Aquat. Biol. 4:235-241. Crossref

Simpfendorfer, C. A., T. R. Wiley, and B. G. Yeiser.

2010. Improving conservation planning for an endangered sawfish using data from acoustic telemetry. Biol. Conserv. 143:1460-1469. Crossref
Simpfendorfer, C. A., B. G. Yeiser, T. R. Wiley, G. R. Poulakis, P. W. Stevens, and M. R. Heupel.

2011. Environmental influences on the spatial ecology of juvenile smalltooth sawfish (Pristis pectinata): results from acoustic monitoring. PLoS ONE 6(2):e16918. Crossref

Whitney, N. M., H. L. Pratt Jr., T. C. Pratt, and J. C. Carrier.

2010. Identifying shark mating behaviour using threedimensional acceleration loggers. Endanger. Species Res. 10:71-82. Crossref

Whitney, N. M., Y. P. Papastamatiou, and A. C. Gleiss.

2012. Integrative multisensor tagging: emerging techniques to link elasmobranch behavior, physiology, and ecology. In Biology of sharks and their relatives, 2nd ed. (J. C. Carrier, J. A. Musick, and M. R. Heithaus, eds.), p. 265-289. CRC Press, Boca Raton, FL.

Whitney, N. M., K. O. Lear, A. C. Gleiss, N. Payne, and C. F. White.

2018. Advances in the application of high-resolution biologgers to elasmobranch fishes. In Shark research: emerging technologies and applications to the field and laboratory (J. C. Carrier, M. R. Heithaus, and C. A. Simpfendorfer, eds.), p. 45-70. CRC Press, Boca Raton, FL.

Whitty, J. M., D. L. Morgan, S. C. Peverell, D. C. Thorburn, and S. J. Beatty.

2009. Ontogenetic depth partitioning by juvenile freshwater sawfish (Pristis microdon: Pristidae) in a riverine environment. Mar. Freshw. Res. 60:306-316. Crossref

Whitty, J. M., J. Keleher, B. C. Ebner, A. C. Gleiss, C. A. Simpfendorfer, and D. L. Morgan.

2017. Habitat use of a Critically Endangered elasmobranch, the largetooth sawfish Pristis pristis, in an intermittently flowing riverine nursery. Endanger. Species Res. 34:211-227. Crossref

Wilson, R. P., C. R. White, F. Quintana, L. G. Halsey, N. Liebsch, G. R. Martin, and P. J. Butler.

2006. Moving towards acceleration for estimates of activity-specific metabolic rate in free-living animals: the case of the cormorant. J. Anim. Ecol. 75:1081-1090. Crossref

Wood, S. N.

2017. Generalized additive models: an introduction with $\mathrm{R}$, 2nd ed., 476 p. Chapman and Hall/CRC, Boca Raton, FL.

Wueringer, B. E., S. C. Peverell, J. Seymour, L. Squire Jr., S. M. Kajiura, and S. P. Collin.

2011. Sensory systems in sawfishes. 1. The ampullae of Lorenzini. Brain Behav. Evol. 78:139-149. Crossref

Wueringer, B. E., L. Squire Jr., S. M. Kajiura, N. S. Hart, and S. P. Collin.

2012. The function of the sawfish's saw. Curr. Biol. 22:R150R151. Crossref 